\title{
A LUTA PELO DIREITO NAS INTERSEÇões DO LITERÁRIO COM O JURÍDICO
}

\author{
THE FIGHT FOR RIGHT IN THE INTERSECTION OF THE LITERARY \\ WITH THE LEGAL
}

\author{
Isaias Francisco de Carvalho*
}

\begin{abstract}
RESUMO: O presente estudo visa analisar o caráter transdisciplinar e não meramente interdisciplinar entre direito e literatura. Partindo da premissa de que a transdisciplinaridade é um conceito que agrega importantes contribuições aos estudos das duas áreas mencionadas, buscamos verificar como se estabelecem as interseções da linguagem jurídica com a literária. Similaridades e interdependências dos dois campos são apontadas, bem como o já antológico caso do judeu Shylock, em O mercador de Veneza, de William Shakespeare, especificamente a partir das considerações de Rudolf von Ihering, em A luta pelo direito.
\end{abstract}

PALAVRAS-CHAVE: Transdisciplinaridade. Ihering. Shylock. Devido processo legal.

ABSTRACT: This work aims to analyze the transdisciplinary - not merely interdisciplinary - character between law and literature. Assuming that transdisciplinarity is a concept that has highly contributed to both fields, we intend to verify how the intersections of the legal language are established with the literary language. Similarities and interdependencies of the two domains are pointed out, as well as the already anthologic case of Shylock, in The merchant of Venice, by William Shakespeare, specifically on the basis of the considerations by Rudolf von Ihering, in Fight for right.

KEYWORDS: Transdisciplinarity. Ihering. Shylock. Due process of law.

" Professor adjunto de Literaturas Anglófonas e de Língua Inglesa na Universidade Estadual de Santa Cruz - UESC (Ilhéus, Bahia). Doutor em Teorias e Crítica da Literatura e da Cultura pela Universidade Federal da Bahia - UFBA. Acadêmico de Direito na Universidade Estadual de Santa Cruz UESC. E-mail: isaiasfcarvalho@gmail.com. 
A interdisciplinaridade já é uma postura prática e conceitual tão aceita que não parece mais relevante colocá-la como argumento justificador de um exercício acadêmico. Entretanto, no caso específico do tema deste trabalho, é grata a constatação de que direito e literatura - ambos campos da linguagem verbal, ambos campos em que a interpretação textual é constituinte - têm sido abordados interdisciplinarmente na academia desde os anos 1970. Desse modo, no presente esforço intelectual de aproximação entre o universo jurídico e a dimensão literária, o caráter de interdisciplinaridade é mais uma vez posto como justificativa, até mesmo porque tenho formação e prática profissional na área das Letras e agora adentro a epistemologia e a práxis de um novo saber - o jurídico. Mas a simples e inevitável interdisciplaridade, em que pese servir como justificativa, não basta ou limita o viés tomado neste trabalho: o caráter transdisciplinar da relação direito e literatura ou, como nos informa Thomas Morawetz (1996), o direito na literatura, a literatura no direito, o direito da literatura, a literatura reformadora do direito e o amálgama entre direito e ficção como fonte de referenciais éticos. E não se deve esquecer o antológico "direito à literatura", de Antonio Candido (1995), que prega o acesso às letras como um direito social fundamental.

De fato, nos chamados "estudos culturais", esse campo polêmico, mas já consolidado nas humanidades e que também permeia parte das pesquisas no campo jurídico, iniciativas de pesquisa e estudo são colocadas em um espectro não apenas interdisciplinar, mas também pós-disciplinar, transdisciplinar e por vezes contradisciplinar (GROSSBERG et al, 1992). Não pretendo, de qualquer modo, abordar as questões referentes à pulsão do prefixo "pós" ou os aspectos do prefixo "contra", mas concentrar as análises no outro prefixo, mais produtivo: "trans", que promove um ambiente mais propício à integração do conhecimento e à humanização do saber acadêmico e científico.

Cabe um breve histórico dos antecedentes da transdisciplinaridade, em Ignacio Gerber (2008, online): O método cartesiano, surgido no século XVII, que predomina até a contemporaneidade, busca a verdade por meios científicos, quando se inicia a proliferação de disciplinas, pois é um método que tem bases na decomposição do todo e na técnica dedutiva. Desse modo, a disciplinaridade levou à pluridisciplinaridade, ou multidisciplinaridade, que se trata da análise de um objeto de uma disciplina específica por várias disciplinas simultaneamente. Em seguida, o conceito de interdisciplinaridade, que se refere à transferência de métodos e conceitos de uma disciplina à outra. Multidisciplinaridade e 
interdisciplinaridade estão no nível da linearidade disciplinar. E chega-se à transdiciplinaridade, que abarca e transcende o que passa por todas as disciplinas no encontro de seus pontos de interseção.

Apesar de ser um vocábulo cunhado originalmente por Jean Piaget, em 1970, no I Seminário Internacional sobre Pluri e Interdisciplinaridade, utilizo aqui, como forma sintética e acabada, a definição proposta por Olga Pombo, do Departamento de Educação da Universidade de Lisboa, para quem transdisciplinaridade significa a

Integração global das várias ciências. À etapa das relações interdisciplinares sucede-se uma etapa superior, que seria a transdisciplinaridade, que não só atingiria as interações ou reciprocidades entre investigações especializadas, mas também situaria estas relações no interior de um sistema total, sem fronteiras estáveis entre as disciplinas. (POMBO, 2009 , online).

A transdisciplinaridade, por esse prisma, é um estágio além da interdisciplinaridade. Mas a potencial quebra de fronteiras entre as disciplinas não implica o caos. Ao contrário, significa que os diferentes campos do saber colaboram entre si, com o intuito de não apenas adicionar conhecimento, mas de poder organizá-lo de modo complexo. A partir desse conceito, podemos pensar as disciplinas e práticas discursivas de literatura e de direito, cada uma por seu turno, como dimensões que já são resultado de processos interdisciplinares individuais. Quando em conjunto, como proposto neste trabalho, compõem, assim, um espaço transdisciplinar plural e integrado.

\section{TERMINOLOGIA DERIVADA DO VOCÁBULO "DISCIPLINA"}

É a partir do vocábulo "disciplina" que vêm diversos desdobramentos lexicais, tais como a da própria transdisciplinaridade - ethos geral deste exercício monográfico -, disciplinaridade, interdisciplinaridade, multidisciplinaridade, pósdisciplinaridade e antidisciplinaridade. Entender cada um desses derivados de disciplina, mesmo que de forma breve, também favorece a compreensão global da proposta de se tomar literatura e direito pelo viés transdisciplinar no âmbito acadêmico e jurídico brasileiro.

Para os estudantes em geral, disciplinas são as diferentes áreas de conhecimento ou conjunto de atividades inseridas no currículo acadêmico. É uma noção próxima das caracterizações que nos oferece Olga Pombo (2009, online). Segundo ela, disciplina pode ser conceituada como um conjunto especializado de saberes que possuem suas características próprias no campo do ensino, da 
formação, dos procedimentos, da metodologia e dos materiais. Disciplina também pode ser conceituada como o tratamento de determinada categoria de fenômenos, no intuito de descrever esses fenômenos e estabelecer possíveis previsões e fazer relações entre eles. Em suma, o vocábulo "disciplina" pode ser tomado como sinônimo de ciência, mesmo que esta geralmente seja associada à atividade investigativa e aquela à prática de ensino das ciências.

Do conceito de disciplina, parte-se para seus desdobramentos, três dos quais serão também conceituados com base em Olga Pombo (2009, online): disciplinaridade, interdisciplinaridade e multidisciplinaridade. Primeiramente, a noção de disciplinaridade, que é a prática científica específica a certo campo homogêneo em busca de novos saberes para substituir antigas noções. É uma postura metodológica.

Por seu turno, o conceito de interdisciplinaridade, o derivado de disciplina mais popularmente conhecido, não aponta simplesmente, por meio do prefixo "inter", a uma pluralidade ou a uma justaposição de disciplinas, mas a um domínio comungado e um elemento de coesão entre saberes diversos. Essa caracterização da interdisciplinaridade implica a participação motivada, pois em comunhão de vontades, de especialistas das várias disciplinas envolvidas. Pressupõe, portanto, abertura intelectual, vez que se deve trabalhar com saberes alheios, com vistas a enriquecimento científico mútuo.

O terceiro dos derivados de disciplina aqui tratados pela contribuição de Olga Pombo (2009, online) é multidisciplinaridade, a qual se distingue de interdisciplinaridade, pois nesse caso se trata, de fato, de disciplinas justapostas, muitas vezes sem relação clara entre si. É como se fosse um estágio anterior à interdisciplinaridade. Esta implica atuação cooperativa e interdependente, e aquela, uma simples troca de ideias.

Quanto aos termos pós-disciplinaridade e antidisciplinaridade (ou contradisciplinaridade), são aqui utilizados para reforçar o aspecto transdisciplinar deste trabalho, como empréstimos do campo dos Estudos Culturais. De fato, nesse campo polêmico, já consolidado nas humanidades e que também permeia parte das pesquisas no campo jurídico, iniciativas de pesquisa e estudo são colocadas em um espectro não apenas interdisciplinar, mas também pós-disciplinar, transdisciplinar e por vezes contradisciplinar (GROSSBERG et al., 1992). Na verdade, os estudos culturais não formam uma disciplina tradicional. Ao contrário, delimitam uma área ativa e agressivamente antidisciplinar - uma característica que de certa forma assegura uma relação permanentemente desconfortável com as disciplinas acadêmicas tradicionais. Ou é um campo que reluta em se tornar também uma disciplina. 
A partir dessas breves considerações, propus como modesto objetivo geral para este artigo a revisão de parte da literatura que aborda os liames de semelhança e familiaridade transdisciplinares entre as áreas jurídica e literária. Como objetivo secundário, mas não menos importante, vez que ilustra o primeiro, propus destacar criticamente a análise feita por Rudolf von Ihering, em A luta pelo direito, sobre a defesa do devido processo legal na cena do julgamento com Antonio e Shylock, em O mercador de Veneza, de William Shakespeare.

\section{DIREITO E LITERATURA: CONCEITUAÇÃo PRELIMINAR}

Condizente com a postura de crítica cultural de caráter transdisciplinar, em que teoria e prática e teoria e sociedade devem ser pensadas imbricadamente, a concepção de direito neste trabalho é de ímpeto antropológico e de cunho sociológico e realista, do modo como o define André Franco Montoro (2000, p. 55): "O direito é um conjunto de regras obrigatórias, que determinam as relações sociais, tal como a consciência coletiva do grupo as representa a cada momento". Esse conceito de direito implica sua submissão a uma dinâmica de transformação em consonância com a sociedade a que pertence.

Dentre as concepções culturalistas do direito, destaca-se também a teoria tridimensional do jusfilósofo brasileiro Miguel Reale (2001, p. 60), segundo o qual o direito engloba dialeticamente três dimensões: um aspecto normativo (o direito como ordenamento), um aspecto fático (o direito como fato, em sua efetividade social e histórica) e um aspecto axiológico (o direito como valor de Justiça). Portanto, norma, fato e valor não podem ser pensados isoladamente, mas sempre em conjunto, o que se coaduna com uma abordagem transdisciplinar tanto do direito quanto da literatura, esta também tomada como fato social e cultural.

Definições cabais e exatas têm sido cada vez mais raras na academia, especialmente na área das humanidades, em que a transdisciplinaridade é, mais do que uma escolha, uma inevitável postura. Com os termos "direito" e "literatura" não poderia ser diferente. Antoine Compagnon nos coloca diante dos impasses e obstáculos na conceituação de literatura, em seu $O$ demônio da teoria: literatura $e$ senso comum (1999, p. 31-33). Inicialmente, Compagnon informa que, em sentido lato, literatura é tudo aquilo que é impresso ou manuscrito, isto é, são todos os livros incluídos na biblioteca. Também engloba o que se denomina literatura oral. Essa concepção de literatura é a tradicional clássica e moderna das "belas-letras" que, para Compagnon, abarcavam todos os campos de atuação da retórica e da poética, incluindo, além da ficção, obras filosóficas, históricas e científicas. Já em seu sentido estrito, há variações ao longo do tempo. Porém, desde o século XIX, literatura tem sido compreendida como 
[...] o romance, o teatro e a poesia, retomando-se à tríade pós-aristotélica dos gêneros épico, dramático e lírico, mas, doravante, os dois primeiros seriam identificados com a prosa, e o terceiro apenas com o verso, antes que o verso livre e o poema em prosa dissolvessem ainda mais o velho sistema de gêneros (COMPAGNON, 1999, p. 32).

Esse sentido de literatura é, assim, a concepção moderna, que é diretamente relacionada ao romantismo, ou seja, da consolidação do caráter relativo, em termos históricos e geográficos, do bom gosto, em contraste à doutrina clássica do cânone estético como eterno e universal. Para a caracterização contemporânea do que é literatura - como total abertura, diálogo e carnavalização - foi um desdobramento consequente. As mesmas transformações foram sofridas pelo campo jurídico, ou seja, de um pedestal dogmático e positivista, moveu-se em direção à cultura concreta da sociedade. Esse percurso levou ao reconhecimento de que tanto literatura quanto direito são produtos socioculturais contextualizados. Desse modo, a literatura não se restringe mais a seu estrato "culto", mas inclui as manifestações da chamada literatura popular, enquanto o direito não se restringe mais ao dogma, mas inclui processos hermenêuticos e interpretativos que levam em conta os contextos socioculturais dos sujeitos.

\section{CULTURA, LITERARIEDADE E AS MARGENS ENTRE O LITERÁRIO E O NÃO LITERÁRIO}

Pelo movimento anglófono dos Estudos Culturais, principalmente a partir da década de 1960, os objetos estéticos passam a ser considerados em seu contexto de produção, reprodução e recepção. Assim, a crítica cultural pode ser colocada como contraste a uma crítica exclusivamente literária (ou jurídica, como extensão). Silviano Santiago (1998, p. 11), a propósito dessa transformação epistemológica em relação à arte e à literatura brasileira, levanta questões referentes a quando essas manifestações humanas deixam de ser literárias e sociológicas para ganhar uma dimensão cultural e antropológica. Também questiona

[...] quando é que se rompem as muralhas da reflexão crítica que separavam, na modernidade, o erudito do popular e do pop? Quando é que a linguagem espontânea e precária da entrevista (jornalística, televisiva, etc.) com artistas e intelectuais substitui as afirmações coletivas e dogmáticas dos políticos profissionais, para se tornar a forma de comunicação com o novo público? (SANTIAGO, 1998, p. 11).

O que interessa aqui não é exatamente a resposta a essas questões, mas as questões mesmas. O movimento do que se considerava arte ou literatura isoladamente em direção à sociedade e à cultura é o interesse central aqui 
para também discutir, nesse contexto, a literatura e o direito em suas relações transdisciplinares. $O$ cotidiano da vida entra tanto na literatura quanto no direito, como se verá adiante. Ou seja, tanto o jurídico quanto o literário são desnudados de seus valores intrínsecos para se tornarem mecanismos de mediação cultural, encorajando o questionamento de identidades e de lugares de poder e de subalternidade, bem como noções canonizadas de valor estético e cultural.

Para Antoine Compagnon (1999, p. 32-33), todo julgamento de valor implica um ato de exclusão. Assim, estabelecer a fronteira entre o literário e o não literário depende do contexto histórico e geográfico. Afirmar que um texto é literário coloca sempre outro que não o é. Obviamente, apesar de não ser totalmente aplicável, é mais realizável a separação entre o que é e o que não é jurídico. E é pertinente repetir que, neste trabalho, as margens entre o literário e o jurídico serão rasuradas e reconstruídas, pelo viés transdisciplinar. Porém, cabe conceituar os termos antes da aventura principal.

Informa-nos mais uma vez Antoine Compagnon (1999, p. 40-4) que foram os formalistas russos que delinearam uma utilização especificamente literária para a língua. Desse modo, a característica distintiva do texto literário é a literariedade, ou seja, o que faz determinada obra uma obra literária. Mas Compagnon afasta o conceito pela dificuldade de sua aplicação, pois "não existem elementos linguísticos exclusivamente literários" (COMPAGNON, 1999, p.42). Para ele, a desfamiliarização trazida pela literatura não é resultado

[...] da utilização de elementos linguísticos próprios, mas de uma organização diferente (por exemplo, mais densa, mais coerente, mais complexa) dos mesmos materiais linguísticos cotidianos. Em outras palavras, não é a metáfora em si que faria a literariedade de um texto, mas uma rede metafórica mais cerrada, a qual relegaria a segundo plano as outras funções linguísticas. (COMPAGNON, 1999, p. 43).

É por isso que o caráter provisório típico da contemporaneidade, tanto no direito quanto na literatura, parece ter tudo para durar, pois não há essência da literatura ou essência do direito. São realidades complexas, heterogêneas e mutáveis. Por isso que, na seção seguinte, problematiza-se também a possibilidade de se considerar o direito como literatura, isto é, o jurídico como ficção e vice-versa.

\section{APROXIMAÇÕES TRANSDISCIPLINARES ENTRE DIREITO E LITERATURA}

Trata-se do que André Trindade e Germano Schwartz (2008) denominam “o encontro entre Themis e Apolo". As relações de similaridade e de interdependência 
da justiça com a poesia (aqui mais apropriadamente poiesis). O plano do discurso judiciário, em suas conexões com o plano literário, aproxima o caráter fictício deste com as abstrações e ambiguidades no caráter deontológico daquele. Na verdade, o "dever-ser" do direito faz com que, na perspectiva hermenêutica da linguagem e da expressão, essas duas disciplinas, em aparência, tão antagônicas, estabeleçam encontros frequentes na prática jurídica e no fazer literário, em mútua ação dialógica (SILVA, 2001). Neste trabalho, encontros em relação transdisciplinar, corroborada também pelo seguinte comentário:

O que se percebe na análise dos textos jurídicos na modernidade, em especial as normas
constitucionais, é que muitas vezes o direito parte de um paradigma ou mesmo tenta
alcançar uma realidade que consiste numa ficção. E é exatamente nesse aspecto que
direito e literatura se aproximam, pois, realidade e ficção literária em alguns momentos
se misturam de tal maneira que se torna difícil distingui-las (FERES; SANTOS, 2008,
p. 4861).

Parece uma bofetada na face dos kelsenianos mais radicais e de positivistas jurídicos de toda sorte. A rasura das fronteiras disciplinares, no caso dos dois campos sob análise, é ainda mais facilitada por serem ambos domínios da linguagem. Nesse sentido, o jurista Luís Roberto Barroso (2002, online) questiona exatamente o tradicional posicionamento intelectual, no âmbito jurídico, de se isolar em sua "autossuficiência excludente" ou, ainda, em seu "narcisismo científico", especialmente de matiz formalista e positivista. A propósito, o vocábulo "modernidade", utilizado na citação de Feres e Santos acima, provavelmente foi empregado no sentido de atualidade ou contemporaneidade, mas a "aproximação entre direito e literatura é recorrente na tradição cultural ocidental. Em tempos pretéritos o vínculo era menos problemático; o homem das leis o era também de letras, e Cícero pode ser o exemplo mais emblemático" (GODOY, 2008, p. 21). Portanto, pode-se considerar o impulso transdisciplinar como um reconhecimento da grandeza dessa prática helênica de mesclar os saberes em nome de uma visão mais ampla do conhecimento: as íntimas relações entre Themis e Apolo.

Pelo viés da cultura, Guilherme Nitschke resgata a noção de obra literária como "cronótopo", delineada por Mikhaïl Bakhtin, ao afirmar a interação do texto com o real por meio dos elos de tempo (krónos) e de espaço (topos). Se o direito é um fenômeno cultural, que se configura na e através da história, relaciona-se com os valores mais significativos de cada época e de cada cultura. Daí concluir-se que é do aspecto histórico da literatura que se consegue a mais produtiva matéria para o direito, especialmente no que se refere aos ordenamentos jurídicos de outros tempos (NITSCHKE, 2008). 
Tantas outras interseções podem ser feitas no diálogo transdisciplinar literatura-direito. Que bastem essas para ilustrar o objetivo central do presente trabalho, além do caso Shylock a seguir, abordado nas margens transdisciplinares, explícita e implicitamente, da história, da religião, do judaísmo, da poesia, do direito, da sociologia etc.

\section{PAIXÃo E LUTA PELO DIREITO: SHYLOCK, UM CASO JURÍDICO CONCRETO NA LITERATURA}

Como se escrevesse literariamente, o jurista Luís Roberto Barroso (2002) propõe uma atitude de busca para os juristas e todos os aplicadores do direito: uma paixão intelectual pelo conhecimento, pois também o direito está no domínio dos sentimentos e das paixões. Defende que se deve harmonizar razão e emoção, ao definir o direito como a positivação dos valores mais elevados da civilização. Assim posto, o direito é um campo apaixonante e apaixonável. Porém, não deixa de tecer críticas ao que chama de "fetiche da legalidade", ou seja, a paixão desenfreada pela norma é destrutiva. Barroso afirma, ainda, que é preciso ter paixão pela linguagem e cita muitos nomes da literatura, com trechos selecionados de Paulo Leminski, Homero, Fernando Pessoa e Eça de Queiroz, entre outros. É nesse campo que prega uma atitude poética ao se elaborar a linguagem do direito, pois a paixão pela palavra é um exercício de estética, sendo que a beleza está na simplicidade, na transparência e na clareza, "nunca na linguagem empolada, pernóstica, arrogante" (BARROSO, 2002, online).

É justamente no campo da paixão e da veemência no uso da linguagem que se pode colocar o opúsculo $A$ luta pelo direito (IHERING, 2009), que nos informa que o direito não se restringe a pressupostos teóricos, mas está na batalha incessante em nome da defesa do jurídico como meio para alcançar a justiça e a paz social, que não se conquistam espontaneamente. A "luta", nesse contexto, significa a relevância da tarefa do indivíduo na busca por justiça, pois é o direito absoluto o que se tem corrompido e negado no direito pessoal - 'direito subjetivo' -, e é esse direito que se deve defender e restaurar. Assim, o direito adquire status de uma força viva, carregado de paixão, no sentido proposto acima.

Rudolf von Ihering aponta, entretanto, que há indivíduos colocados em situações nas quais a exigência de uma luta incessante pelo direito é posta, mas que tomam uma decisão completamente oposta ao natural combate - escolhem a postura pacífica a um direito conquistado tão arduamente por gerações inteiras que lhe antecederam. Para Ihering, as maiores conquistas que se podem recordar na história do direito não foram alcançadas sem uma luta das mais violentas e 
que geralmente duraram séculos, e quase sempre regadas a banhos de sangue. Portanto, a defesa do direito é um dever da própria conservação moral do indivíduo e de sua comunidade. A luta pelo direito já se tornou uma obra canônica do direito, pois, nela, Rudolf von Ihering também faz incursões pertinentes e ilustrativas no âmbito da literatura e da História. Daí ser a referência literária nesse texto aqui tomado como emblemático de um exemplar concreto de transdisciplinaridade, pois, no caso concreto de Shylock, é a questão judaica, no contexto da Idade Média e espelhado para antes e depois, que se tem colocada pela via literária, mas que a história e o direito estão diretamente envolvidos, além de possíveis análises abertas a várias outras disciplinas das humanidades.

No caso da literatura, paixão e luta se misturam no ímpeto de vingança e no ódio que levam Shylock, um dos personagens mais densos criados por William Shakespeare, em $O$ mercador de Veneza, a exigir no tribunal seu direito de cortar a sua libra de carne nas entranhas de Antônio. Por mais pervertido ou fetichista que pareça ser, é a linguagem, afirma Ihering, que o sentimento do direito lesado sempre falará. É o poder de persuasão de que o direito é sempre direito.

Não poderia me furtar a trazer para a discussão do "caso concreto" de Shylock a visão de um teórico e crítico da linguagem literária para dialogar com essa outra do jusfilósofo. Erich Auerbach (1976), a propósito da caracterização da mistura de estilos entre o trágico e cômico (e entre o sublime e o baixo) em Shakespeare, afirma que, de modo diverso da Idade Média, todas as personagens que o dramaturgo inglês representa como trágicas e sublimes são de alta posição social. Por esse viés, Shylock não poderia ser considerado trágico, mas cômico. Porém, Shylock é um caso limítrofe, pois, apesar de não ser exatamente um cidadão comum devido a sua posição social, é um pária: um judeu agiota, portanto de posição social vil. Para Auerbach, Shylock é representado inicialmente de modo trágico, especialmente em sua veemência na defesa de seu direito diante da letra da lei de Veneza, para no final ser relegado a uma situação cômica:

Shakespeare deixa que os motivos trágicos caiam, no fim, numa negligente e olímpica alegria [...]. Sem dúvida, os atores que querem fazer de Shylock um herói trágico estão errados [...]. Para [Shakespeare], Shylock é, do ponto de vista da sua posição social e do ponto de vista estético, uma figura baixa, indigna do tragic. (AUERBACH, 1976, p. 280).

Isso implica uma concepção do trágico-sublime de cunho estritamente aristocrático por parte de Shakespeare. Aí residiria uma pequena divergência entre Ihering e Auerbach na visão sobre Shylock: enquanto o jusfilósofo afirma 
que há um interesse puramente trágico nesse caso de luta pelo direito e injustiça ao final do julgamento, o crítico literário expõe o caráter dominante de comicidade na representação shakespeareana da condição ignóbil do judeu naquela sociedade e naquele período histórico. Entretanto, divergências à parte, esses dois analistas do caso Shylock são um reforço à noção transdisciplinar do relacionamento entre direito e literatura. Em comum com Ihering, Auerbach propõe que "o pária Shylock não apela para o direito natural, mas para a injustiça existente; quanta dinâmica atualidade há numa tal ironia amarga, trágica!" (AUERBACH, 1976, p. 289). E também de modo exclamativo: “Quantas reflexões não nos deve sugerir este drama legal!" (IHERING, 2009, online). Afinal, nesse caso, o ficcional e o jurídico estão imbricados em vários ângulos teóricos, literários e jurídicos, todos úteis e atuais para os estudiosos e aplicadores do direito.

Desse modo, é relevante lembrar o que Erich Auerbach, teórico da linguagem literária, ensina em sua Mimesis: "Para [Shakespeare], Shylock é, do ponto de vista da sua posição social e do ponto de vista estético, uma figura baixa, indigna do trágico" (AUERBACH, 1976, p. 280), este que é o estilo do sublime, do elevado e do aristocrático. Apesar de ser o judeu pária da sociedade, é a motivação apaixonada de um homem consciente de que não luta só por sua individualidade, mas por uma ideia de direito. E Ihering nos diz que as palavras que o poeta coloca na boca de Shylock transformam completamente sua pretensão em uma questão cujo objeto é exatamente o direito de Veneza. Eis o que Shylock diz a esse respeito, na cena no tribunal:

SHYLOCK - Já expus a Vossa Graça o que pretendo, como jurei por nosso santo Sábado cobrar o estipulado pela multa. Se mo negares, que com o risco seja das leis e liberdades de Veneza. [...] Se esse direito me negardes fora com vossas leis! São fracos os decretos de Veneza. (SHAKESPEARE, IV, 1).

Portanto, não é o judeu que reclama a seu pedaço de carne, mas a própria lei veneziana que se coloca no tribunal, porque o direito de Shylock, nesse caso concreto, e o direito de Veneza são apenas um, perecendo o segundo se perece o primeiro. Mas, no final, Shylock vislumbra sua desgraça e percebe que não passa de um reles judeu da Idade Média a quem não se deve o direito da justiça, mas o da ilusão. É a literatura também servindo como denúncia de injustiças históricas e culturais. Além de tantas outras reflexões transdisciplinares possíveis, entre elas, questões contemporâneas de geopolítica.

Não pretendo que pareça uma leitura descabida, mas parto do pressuposto de que a condição dos judeus de fugitivos e perseguidos em quase todas as partes do 
mundo é a questão mais mal resolvida da história da humanidade. É sintomática a visão de Karl Marx, há cerca de um século e meio, sobre a dificuldade de solução da chamada "questão judaica" (MARX, 2003, p. 16).

Como se pode observar das várias crises geopolíticas em que o Estado de Israel está atualmente envolvido, essa questão judaica não está resolvida ainda hoje, nem parece que vai ser no horizonte próximo. De fato, o atual Estado de Israel, além da dolorosa questão palestina (em que desempenha um papel mais de vilão do que de vítima), pode ser o epicentro de uma possível quarta guerra mundial, com o Irã negando a existência do holocausto e pregando a eliminação daquele país, para citar apenas um aspecto dessa problemática questão judaica que se perpetua. São também sintomáticas em Marx as fartas pistas de ranço anti-semita - com relação aos judeus alemães, especificamente, e seu desejo de emancipação. Em seu intento de se afastar da formulação teológica da questão, Marx coloca: "Qual a base profana do judaísmo? A necessidade prática, o interesse pessoal. Qual o culto mundano do judeu? A traficância. Qual o seu deus mundano? O dinheiro" (MARX, 2003, P. 39). E mais adiante: "Qual a verdadeira base da religião judaica? A necessidade prática, o egoísmo" (MARX, 2003, p. 41). É um espaço de quase um milênio entre o contexto dado para os judeus em $\boldsymbol{O}$ mercador de Veneza e essa caracterização marxista ácida, mas o imaginário em relação aos judeus se mantém inalterado.

De qualquer sorte, não é a denúncia ou a discussão de um suposto antisemitismo de Shakespeare, em sua ridicularização do judeu Shylock, que me proponho a discutir nesse caso. Voltemos a Ihering, para quem se trata do "entusiasmo apaixonado de um homem que tem consciência de que não luta só por sua pessoa, mas também por uma ideia" (IHERING, 2009, online). A libra de carne que Shylock reclama tem como base o título ou a lei que ele representa, ponto no qual há a determinação da "[...] verdadeira relação do direito sob o ponto de vista objetivo e subjetivo, e a significação da luta pela sua defesa melhor do que poderia fazê-lo qualquer filósofo" (IHERING, 2009, online). Interessante para a realidade jurisprudencional ainda hoje é refletir sobre a opressão do direito positivo de que Shylock é vítima. Para citar Ihering:

[...] o que há de mais horrível é que esse homem, que esse infeliz judeu da Idade Média crê no direito, podendo-se dizer mesmo que como um cristão. A sua fé é tão inquebrantável e firme como uma rocha; nada a faz abalar; o próprio juiz a alimenta até o momento em que se resolve a catástrofe e o fulmina como um raio. Então contempla a sua desgraça e vê que só é um mísero judeu da Idade Média a quem se nega a justiça, iludindo-o. (IHERING, 2009, online). 
Finalmente, abatido e vacilante, concordo com Ihering de que o direito de Veneza sofre uma humilhação na pessoa de Shylock, ou seja, não é o judeu Shylock que se abate nessa cena, mas um indivíduo representante do judeu humilhado durante a Idade Média que clama em vão por justiça. É esse tipo de indivíduo que nos faz pensar nos tantos injustiçados nos tribunais, pela falta de acesso apropriado à justiça e pelas múltiplas interpretações que a letra da lei pode tomar na eloquência dos que dominam os trâmites legais. A literatura está repleta desses casos, mas a realidade jurídica ainda mais.

\section{CONSIDERAÇÕES FINAIS}

Para finalizar, sem de modo algum esgotar o assunto, cabe a reiteração do escopo conceitual de transdisciplinaridade na relação entre direito e literatura aqui utilizado. Os campos jurídico e literário, se possível de serem pensados isoladamente, mantêm seus liames interdisciplinares com as diversas outras áreas do saber, principalmente a Filosofia e demais Ciências Sociais e Humanas.

Quando pensados e estudados em conjunto, já perpassados por esses outros saberes, o direito e a literatura, como campos da linguagem e do discurso, realizam uma simbiose transdisciplinar em prol de atitudes mais holísticas e humanizadoras diante do pensamento e da interpretação das realidades. Recomenda-se, portanto, que todo estudioso e/ou aplicador do direito visite as fontes literárias enquanto lida com os textos mais estritamente jurídicos. Do mesmo modo, o literato ou fruidor da literatura pode considerar a formação de seu ordenamento jurídico nas representações culturais contidas nos textos lidos ou analisados. É ler para crer.

\section{REFERÊNCIAS}

AUERBACH, Erich. O príncipe cansado. In: - Mimesis: a representação da realidade na literatura ocidental. São Paulo: Perspectiva, 1976. p. 277-297.

BARroSO, Luís Roberto. Direito e paixão. In: Mundo Jurídico, jul. 2002. Disponível em: <www.mundojuridico.adv.br>. Acesso em: 19 nov. 2009.

CANDIDO, Antonio. Direito à literatura. In: . Vários escritos. 3. ed. São Paulo: Livraria Duas Cidades, 1995.

COMPAGNON, Antoine. O demônio da teoria: literatura e senso comum. Tradução de Cleonice Paes Barreto Mourão. Belo Horizonte: Editora UFMG, 1999.

FERES, Anaximandro Lourenço Azevedo; SANTOS, Anderson Avelino. A literatura desafia o direito. Grande sertão: veredas - uma antecipação do problema sócio-político de segurança pública no Brasil. Brasília: Anais do XVII Congresso Nacional do CONPEDI, novembro de 2008. p. 4860-4872. 
GERBER, Ignacio. Psicanálise e transdisciplinaridade. Instituto de Estudos da ComplexidadeIEC, 5 maio 2008. Disponível em: <http://www.iecomplex.com.br>. Acesso em: 17 nov. 2009.

GODOY, Arnaldo Sampaio de Moraes. Direito e literatura. In: Revista CEJ, Brasília, n. 22, jul./ set. 2003. p. 133-136.

. Direito e literatura: os pais fundadores - John Henry Wigmore, Benjamin Nathan Cardozo e Lon Fuller. In: TRINDADE, André; SCHWARTZ, Germano. Direito e literatura: o encontro entre Themis e Apolo. Curitiba: Juruá, 2008. p. 21-49.

Grossberg, L., NELSON, C., TREICHLER, P. Cultural Studies: an introduction. In: (Ed. and introd.). Cultural Studies. London/New York: Routledge, 1992. p.1-16.

IHERING, Rudolf von. A luta pelo direito. Conferência. Viena, 1872. Disponível em: <www. ebooksbrasil.com>. Acesso em: 23 mar. 2009.

MARX, Karl. A questão judaica. In: Manuscritos econômico-filosóficos. São Paulo: Martin Claret, 2003. p. 13-44.

MONTORO, André Franco. Introdução à ciência do direito. 25. ed. São Paulo: Revista dos Tribunais, 2000.

MORAWETZ, Thomas. Law and literature. In: PATTERSON, Dennis (Ed.). A companion to Philosophy of law and legal theory. Malden: Blackwell, 1996.

NITSCHKE, Guilherme Carneiro Monteiro. Entre a lei e o juiz: justiça, ciência jurídica e "o processo Maurizius". Brasília: Anais do XVII Congresso Nacional do CONPEDI, novembro de 2008. p. 2068-2102.

POMBO, Olga (Org.). Contribuição para um vocabulário sobre interdisciplinaridade. Departamento de Educação, Universidade de Lisboa. Portugual. Disponível em: <http://www.educ.fc.ul.pt/ docentes/opombo/mathesis/vocabulario-interd.pdf>. Acesso em: 20 nov. 2009.

SANTIAGO, Silviano. Democratização no Brasil - 1979-1981 (cultura versus arte). In: ANTELO et al. Declínio da arte e ascensão da cultura. Florianópolis: ABRALIC/Letras Contemporâneas, 1998. p. 11-23.

SHAKESPEARE, William. O mercador de Veneza. Edição Ridendo Castigat Mores. Disponível em: <http://www.ebooksbrasil.org/eLibris/mercador. html\#mv4l>. Acesso em: 23 nov. 2009.

SILVA, Joana Aguiar e. A prática jurídica entre direito e literatura. Coimbra: Almedina, 2001.

TRINDADE, André; SCHWARTZ, Germano. Direito e literatura: o encontro entre Themis e Apolo. Curitiba: Juruá, 2008.

Recebido: maio 2013 